\title{
Combining motor imagery with action observation training does not lead to a greater autonomic nervous system response than motor imagery alone during simple and functional movements: A randomized controlled trial
}

Ferran Cuenca-Martínez ${ }^{\text {Corresp., }}{ }^{1,2}$ ， Luis Suso-Martí ${ }^{1,2}$, Mónica Grande-Alonso ${ }^{1,2}$, Alba París-Alemany ${ }^{1,2,3,4}$, Roy La Touche ${ }^{\text {Corresp. } 1,2,3,4}$

1 Departamento de Fisioterapia, Centro Superior de Estudios Universitarios La Salle, Universidad Autónoma de Madrid, Madrid, Spain

2 Motion in Brains Research Group, Institute of Neuroscience and Sciences of the Movement (INCIMOV), Centro Superior de Estudios Universitarios La

Salle, Universidad Autónoma de Madrid, Madrid, Spain

3 Instituto de Neurociencia y Dolor Craneofacial (INDCRAN), Madrid, Spain

4 Instituto de Investigación Sanitaria del Hospital Universitario La Paz (IdiPAZ), Madrid, Spain

Corresponding Authors: Ferran Cuenca-Martínez, Roy La Touche

Email address: fecuen2@gmail.com, roylatouche@yahoo.es

Both motor imagery $(\mathrm{MI})$ and action observation $(\mathrm{AO})$ trigger the activation of the neurocognitive mechanisms that underlie the planning and execution of voluntary movements in a manner that resembles how the action is performed in a real way. The main objective of the present study was to compare the autonomic nervous system (ANS) response in an isolated $\mathrm{MI}$ group compared to a combined $\mathrm{MI}+\mathrm{AO}$ group. The mental tasks were based on two simple movements that are recorded in the revised movement imagery questionnaire in third-person perspective. The secondary objective of the study was to test if there was any relationship between the ANS variables and the ability to generate mental motor imagery, the mental chronometry and the level of physical activity. The main outcomes that were measured were heart rate, respiratory rate and electrodermal activity. A Biopac MP150 system, a measurement device of autonomic changes, was used for the quantification and evaluation of autonomic variables. Forty five asymptomatic subjects were selected and randomized in 3 groups: isolated $\mathrm{MI}, \mathrm{MI}+\mathrm{AO}$ and control group (CG). In regards to the activation of the sympathetic nervous system (SNS), no differences were observed between $\mathrm{MI}$ and $\mathrm{MI}+\mathrm{AO}$ groups $(p>.05)$, although some differences were found between both groups when compared to the CG $(p<.05)$. Additionally, even though no associations were reported between the ANS variables and the ability to generate mental motor imagery, moderate-strong positive associations were found in mental chronometry and the level of physical activity. Our results suggest that $\mathrm{MI}$ and $\mathrm{MI}+\mathrm{AO}$, lead to an activation of the SNS, although there are no significant differences between the two groups. Based on results obtained, we suggest that tasks of low 
complexity, providing a visual input through the $\mathrm{AO}$ does not facilitates their subsequent motor imagination. A higher level of physical activity as well as a longer time to perform mental task, seem to be associated with a greater increase in the ANS response. 
1 Combining motor imagery with action observation training does not lead to a 2 greater autonomic nervous system response than motor imagery alone during 3 simple and functional movements: A randomized controlled trial.

4

5 Ferran Cuenca-Martínez ${ }^{1-2}$; Luis Suso-Martí1-2; Mónica Grande-Alonso ${ }^{1-2}$; Alba Paris-Alemany ${ }^{1-}$ 6 4; Roy La Touche ${ }^{1-4 *}$.

*Corresponding author: Roy La Touche

Address: Facultad de Ciencias de la Salud, Centro Superior de Estudios Universitarios La Salle, Calle la Salle, nº 10, 28023 Madrid, Spain.

Telephone: (+34) 917401980 Fax: (+34) 913571730

E-Mail: roylatouche@yahoo.es 
24 Abstract

Both motor imagery (MI) and action observation (AO) trigger the activation of the neurocognitive mechanisms that underlie the planning and execution of voluntary movements in a manner that resembles how the action is performed in a real way. The main objective of the present study was to compare the autonomic nervous system (ANS) response in an isolated MI group compared to a combined $\mathrm{MI}+\mathrm{AO}$ group. The mental tasks were based on two simple movements that are recorded in the revised movement imagery questionnaire in third-person perspective. The secondary objective of the study was to test if there was any relationship between the ANS variables and the ability to generate mental motor imagery, the mental chronometry and the level of physical activity. The main outcomes that were measured were heart rate, respiratory rate and electrodermal activity. A Biopac MP150 system, a measurement device of autonomic changes, was used for the quantification and evaluation of autonomic variables. Forty five asymptomatic subjects were selected and randomized in 3 groups: isolated $\mathrm{MI}, \mathrm{MI}+\mathrm{AO}$ and control group (CG). In regards to the activation of the sympathetic nervous system (SNS), no differences were observed between MI and MI+AO groups $(p>.05)$, although some differences were found between both groups when compared to the CG $(p<.05)$. Additionally, even though no associations were reported between the ANS variables and the ability to generate mental motor imagery, moderate-strong positive associations were found in mental chronometry and the level of physical activity. Our results suggest that $\mathrm{MI}$ and $\mathrm{MI}+\mathrm{AO}$, lead to an activation of the SNS, although there are no significant differences between the two groups. Based on results obtained, we suggest that tasks of low complexity, providing a visual input through the AO does not facilitates their subsequent motor imagination. A higher level of physical activity as well as a longer time to perform mental task, seem to be associated with a greater increase in the ANS response. 
54

55

56

57

58

59

60

61

62

63

64

65

66

67

68

69

70

71

72

\section{Introduction}

Motor imagery (MI) is defined as a dynamic mental process that involves the representation of an action, in an internal way, without its actual motor execution (Decety, 1996). The action observation (AO) evokes an internal, real-time motor simulation of the movements that the observer is perceiving visually (Rizzolatti \& Sinigaglia, 2010; Buccino, 2014). Both mental processes trigger the activation of the neurocognitive mechanisms that underlie the planning and execution of voluntary movements in a manner that resembles how the action is performed in a real manner (Stephan et al., 1995; Luft et al., 1998; Lotze et al., 1999; Wright, Williams \& Holmes 2014).

Both observation and imagination share a great number of common mental processes based primarily on sensory perception, and the information stored by memory systems (Jeannerod, 2001). The activation of the motor command during a mental practice does not induce an active movement probably due to an inhibitory mechanism in the primary motor cortex on the descending corticospinal tract pathways. Nevertheless, whereas some studies did not report primary motor cortex activations during MI, others found low involvement or relevant activation, showing some discrepancies (Guillot \& Collet, 2005a; Guillot, Di Rienzo, Macintyre, Moran \& Collet, 2012).

The practice of mental training involves a component of the autonomic nervous system (ANS). Autonomic activation during motor imagery appears to be centrally controlled (Decety et al., 2013). The sympathetic pathways to the heart are modulated by the activity of the anterior cingulate cortex, and cardiovagal activity is under the control of the ventral medial prefrontal cortex (Wong, Massé, Kimmerly, Menon, \& Shoemaker, 2007). Electrodermal activity is mediated by neural networks involving the prefrontal, insular, and parietal cortices, and limbic structures, including the cingulate and medial temporal lobe, along with the amygdala and the hippocampus (Critchley, 2002). The neural substrate for these peripheral autonomic responses is associated with motivational and affective states which, in turn, mediate motor imagery.

It has been shown that both MI and AO lead to changes in the ANS that cause sympathetic responses, although the neurophysiological bases remain uncertain and are still based on hypotheses (Beyer et al., 1990; Decety et al., 1991; Lang et al., 1993; Thill et al., 1997; Bolliet, 
83 Collet \& Dittmar, 2005; Collet et al. 2013). The functional relations between both neurocognitive 84 processes and the sympathetic nervous system (SNS) could be based on a preparation phase in which, the activation of the SNS, happens to a near effort and, therefore, to a close energy expenditure in physiological processes (i.e., cardiorespiratory adaptations, and anticipated adaptations in body temperature and sweat rate) which will take place in order to face said metabolic changes produced by the voluntary movement itself. In addition, several hypotheses have been described regarding the notion that the SNS not only has the quantitative objective of providing energy to the muscle effectors, but that it also qualitatively and specifically designs and adapts the parameters on demand in an attempt to save the energy provided for each precise motor execution. (Decety et al., 1991, 1993; Collet et al., 2013).

Taking into account that both MI and AO cause ANS response that induce an increase in heart rate, blood pressure, respiratory rate and electrodermal activity (Lang et al., 1993; Paccalin \& Jeannerod, 2000; Bolliet, Collet \& Dittmar, 2005; Papadelis et al., 2007; Brown, Kemp \& Macefield., 2013). Previous findings using fRMI reported that MI and AO + MI each have a unique neural signature, involving greater neural activity for $\mathrm{AO}+\mathrm{MI}$ in the bilateral cerebellum compared with MI alone. In addition, in areas such as the supplementary motor cortex and the left precentral gyrus, AO + MI showed increased activity compared with MI independently (Taube et al., 2015). Research using multi-channel electroencephalographic (EEG) recordings has also reported more pronounced electrophysiological activity over primary sensorimotor and parietal regions in the mu/alpha and beta frequency bands for $\mathrm{AO}+\mathrm{MI}$, relative to $\mathrm{MI}$ in isolation (Eaves et al., 2014). In addition, research into observation and imagery effects using single-pulse transcranial magnetic stimulation (TMS) over the motor cortex showed that AO + MI produces significantly greater facilitation of corticospinal excitability compared with MI alone (Sakamoto et al., 2009). Therefore, our hypothesis is that the combination of MI and AO induces an autonomic response shift greater than MI does in isolation.

The main objective of this study was to compare the results obtained from intervention groups on the subject of the sympathetic activation of the ANS in a program that combined MI with AO, in contrast to an isolated MI program on asymptomatic subjects. The secondary objective of the present study was to explore whether there is any relationship between the ANS variables and the ability to generate motor imagery, the mental chronometry, and the level of physical activity. 


\section{Material \& Methods}

\section{Study Design}

115 The present study was a randomized controlled trial. The study was planned and performed in 116 accordance with the requirements of the CONSORT (Consolidated Standards of Reporting 117 Trials) statement (Schulz et al., 2010).

\section{Recruitment of Participants}

119 A sample of asymptomatic subjects was obtained from La Salle University and from the 120 Community of Madrid through media and social networks, posters, brochures, and emails. The 121 subjects were recruited between March and June of 2017. The inclusion criteria were as follows: 122 healthy and with no pain subjects, and age between 18 and 60 . The exclusion criteria included 123 the following: a) subjects who presented systemic, cardio-respiratory, central nervous system or 124 rheumatic diseases, or those who presented any musculoskeletal pathology with a source of 125 symptoms at the time of the study; b) underage subjects; c) subjects with pain at the time of the 126 study; and d) subjects who were not in full use of their mental faculties and thus were not able to 127 perform the intervention of the study.

128 Informed written consent was obtained from all subjects prior to inclusion. All participants were 129 given an explanation of the study procedures, which were planned under the ethical standards of 130 the Helsinki Declaration, and which had been approved by the ethics committee of the La Salle 131 University Center for Higher Education (CSEULS-PI-008). The trial was registered with the 132 United States National Institutes of Health Clinical Trials Registry, with the registration number 133 NCT03232879.

\section{Randomization}

135 Randomization was performed using a computer generated random sequence table with a 136 balanced three-block design (GraphPad Software, Inc., CA, USA). A statistician generated the 137 randomization list, and once the initial assessment and inclusion of the participants were 138 completed, the included participants were randomly assigned to any of the three groups using the 139 random sequence list (MI + AO, only MI or the control group) (Figure 1). 


\section{MI in isolation}

142 All the subjects in the MI group were informed of the procedure at the beginning of the 143 intervention, which consisted of the following: first, the subjects were supine for 5 minutes in 144 order to achieve a baseline condition. After that, they sat for two more minutes. Afterwards, two consecutive 30 seconds visual MI tasks were performed, both based on two movements that are recorded in the revised movement imagery questionnaire in third-person perspective, which is based on the representation of somebody performing a movement.

148 The first movement chosen for mental practice, starting from a standing up position, consisted of raising the right knee as high as possible and then returning to the starting position. The second movement, starting from a standing up position, and with arms extended along the head, consisted of bending the trunk while trying to touch their toes with their hands and then returning to the initial position. Finally, at the end of the mental training the subjects were at rest for 3 more minutes. Hence, the total time of the intervention was 11 minutes (Figure 2).

This group, in addition to the intervention with MI previously described, underwent AO training through the following procedure: before the subjects performed the MI practice, they were presented with a 30 seconds video that displayed the motor task that they ought to imagine later in third-person perspective. A video was played prior to the first practice of imagination and after the second mental practice, a second video was shown. Thus, in this combined group of MI and AO the intervention lasted 12 minutes (Figure 2).

Control Group

162 The subjects included in the control group (CG) had their neurovegetative variables recorded 163 without having undergone any intervention, and they followed the same measurement times as the two previous groups.

\section{Procedures}


166 After giving their consent to partake in the study, all the participants received a set of 167 questionnaires prior to the intervention. These included a sociodemographic assessment, as well 168 as an evaluation of their physical activity and of their ability to generate kinesthetic and visual 169 MI. The questionnaires given were the following: the Spanish validated version of the 170 International Questionnaire of Physical Activity (IPAQ) and the Spanish validated version of the 171 Revised Movement Imagery Questionnaire (MIQ-R). The latter was given to the participants 172 after the intervention, where the time spent for each task of imagination was also recorded. A 173 Biopac MP150 system, a device to measure autonomic activity, was used for the recordings and 174 processing of the autonomic variables.

175 Five measurements were taken for each participant: the first of them was taken after lying down 176 for 5 minutes; the second, after sitting for 2 minutes; the third, after finishing the first 30 seconds 177 task of motor imagination; the fourth, after finishing the second 30 seconds task of motor 178 imagination; and, finally, the fifth measurement was taken 3 minutes after finishing the mental 179 exercise.

180 The Biopac MP150 system has an internal microprocessor to control the data acquisition and 181 communication with the computer. There are 16 analog input channels, 2 analog output channels, 18216 digital channels that can be used for either input or output, and an external trigger input. The 183 digital lines can be programmed as either inputs or outputs and function in 8 channel blocks. 184 Block 1 (I/O lines 0 through 7) can be programmed as either all inputs or all outputs, independently of block 2 (I/O lines 8 through 15$)$.

186 Each condition involved a series of inter-sampling intervals (ISIs). In each condition, the first two ISIs (Pre and Pre-Pre', 420 seconds) was the baseline (rest) period; the next two ISIs (Pre'188 ${ }^{1 s t} I$ and ${ }^{1 s t} I-{ }^{2 n d} I, 30$ seconds each) was the intervention period. Finally, the last ISI ( ${ }^{2 n d}$ I-Post, 180 seconds) was the return to calm phase. Autonomic parameters were continuously monitored and 190 were sampled every 30 seconds. In the first two ISIs, the Pre interval lasted 300 seconds. Ten measurements were taken, and the device calculated a mean of the 10 measurements. The PrePre' interval was measured in the same way (120 seconds, 4 measurements). In this way, two 193 basal measurements were obtained, the first with the participant lying down and second with the 194 participant sitting. Then, regarding the two subsequent ISIs corresponding to the intervention 195 period, the device averaged the values over intervals of 30 seconds where 5 values per second 
196 were registered during the total intervention time and an average value was automatically

197 obtained after each 30-second interval Thus, two measurements were taken, one every 30

198 seconds (the first relative to the first mental task and the second relative to the second). Finally,

199 the last ISI ( ${ }^{2 n d}$ I-Post, 180 seconds) value was obtained in the same way as the baseline data. The

200 procedure was similar to that performed by Decety (1993).

201 Previous research has shown how after MI intervention, the LF/HF ratio as an index of ANS 202 activity returned to the resting level. Therefore, the device was programmed to record the ANS 203 activity values concurrent with the MI session; the measurements are the mean of these values 204 (Bunno et al., 2015).

205 All measurements were taken in a sitting position except for the first one that was taken in a 206 lying position. The measured variables were: 1) heart rate (HR); 2) respiratory rate (RR); and 3) 207 the electrodermal activity (EDA).

208

209

210

211

212

213

214

215

216

217

218

219

220

221

222

223

224

Primary Outcomes

\section{Autonomic Nervous System Variables}

The main outcomes that were measured were HR, RR, and EDA. The recording of these variables was performed to objectify the changes produced in the ANS during the performance of the motor mental practice in both groups. The EDA was measured through the use of two electrodes that recorded changes in conductance through the skin located at the palmar location. They were attached with a distance of $3 \mathrm{~cm}$ in between thenar and hypothenar eminence of the dominant hand (Boucsein et al., 2012). They were disposable snap electrodes pre-gelled with isotonic gel ( $\mathrm{Ag} / \mathrm{AgCl}$ contact). The size was $27 \mathrm{~mm}$ wide x $36 \mathrm{~mm}$ long x $1.5 \mathrm{~mm}$ thick. Contact: $11 \mathrm{~mm}$ diameter. Gel cavity: $16 \mathrm{~mm}$ diameter x $1.5 \mathrm{~mm}$ deep. The transducer (EDA100C) operates by applying a fixed 0.5 Volts DC across the two electrodes and then measures the current flowing between the two electrodes. Given the voltage (V) is fixed, from Ohms Law, the conductance $(\mathrm{G})$ will be proportional to the current $(\mathrm{I}): \mathrm{G}=\mathrm{I} / \mathrm{V}=\mathrm{I} / 0.5 \mathrm{~V}$. Circuitry then converts the detected current to a voltage so it can be measured by the MP device. The software performs the necessary scaling and unit conversion. The RR was measured through a respiratory effort transducer, SS5LB model. It was placed around the chest like a strap passing over the xiphoid process (La Touche et al., 2013). Finally, the HR was measured by three 
225 electrodes located in the left area of the chest: one placed one centimetre under the left

226 sternoclavicular joint, a second one positioned two centimetres under the left acromioclavicular

227 joint, and a third one was located five centimetres under the first electrode, in the sixth left

228 sternocostal joint (Niendorf, Winter \& Frauenrath., 2012). The electrodes were disposable snap

229 electrodes pre-gelled with isotonic gel ( $\mathrm{Ag} / \mathrm{AgCl}$ contact). The size was $40 \mathrm{~mm}$ (diameter), with

230 foam tape $(1.5 \mathrm{~mm}$ thick) backing, and incorporated a gel cavity (16 mm diameter x $1.5 \mathrm{~mm}$

231 deep).

\section{Secondary outcomes}

\section{Visual and Kinesthetic Motor Imagery Ability}

234 MIQ-R has 4 movements repeated in two subscales, a visual and a kinesthetic one. Additionally, 235 a score between 1 and 7 is assigned, with 1 representing difficulty in picturing the motor image 236 or difficulty in feeling the movement previously made, and 7 representing the maximum ease. 237 The internal consistencies of the MIQ-R have been consistently adequate with Cronbach's $\alpha$ 238 coefficients ranging above 0.84 for the total scale, 0.80 for de visual subscale and 0.84 for the 239 kinesthetic subscale (Campos \& González, 2010).

\section{Mental Chronometry}

241 Mental chronometry evaluation was also used to measure the subject's motor imagery ability. 242 Using a stopwatch, the time spent for performing each MIQ-R task was recorded. Time recorded 243 corresponds to the interval between the command to start the task, given by the evaluator, and 244 the verbal response of conclusion of the task, given by the subject. Mental chronometry is a 245 reliable behavioral task that has previously been employed to collect an objective measure of MI 246 ability (Guillot \& Collet, 2005b; Malouin et al., 2008; Williams et al., 2015).

248 The level of physical activity was objectified through the IPAQ questionnaire, which allows the 249 subjects to be divided into three groups according to their level of activity, which can be high, 250 moderate, and low or inactive (Roman-Viñas et al., 2010). 251 This questionnaire has shown an acceptable validity to measure total physical activity. Therefore, 
252 the psychometric properties of the questionnaire were accepted for use in studies that required

253 the measurement of physical activity.

254 Sample Size Calculation

255 The sample size was estimated with the program $G^{*}$ Power 3.1.7 for Windows (G*PowerC from

256 University of Dusseldorf, Germany) (Faul et al., 2007). The sample size calculation was

257 considered as a power calculation to detect between-group differences in the primary outcome

258 measures (skin conductance). We considered 3 groups and 4 measurements for primary

259 outcomes to obtain $95 \%$ statistical power (1- $\beta$ error probability) with an $\alpha$ error level probability

260 of .05 using analysis of variance (ANOVA) of repeated measures, within-between interaction,

261 and an effect size of $\eta_{p}{ }^{2}=0.25$ obtained from a pilot study conducted with 8 participants (4 per

262 group). This generated a sample size of 15 participants per group (a total of 45 participants).

\section{Data Analysis}

264 The data analysis was performed using the Statistics Package for Social Science (SPSS 22.00, 265 IBM Inc., USA).

266 For data analysis, we used a confidence interval of $95 \%$, considering all those values that had a $p$

267 value of less than .05 to be statistically significant.

268 Descriptive statistics that were used to summarize data for continuous variables are presented as mean \pm standard deviation and the $95 \%$ confidence interval, while categorical variables are presented as an absolute number or relative frequency percentage. A chi-square test with residual analysis was used to compare categorical variables. The normal distribution of all primary and secondary measures data was assessed using the Shapiro-Wilk test $(p>.05)$. In order to compare the means of the ANS measures, the repeated measures ANOVA test was used. The effect size

274 (Cohen's $d$ ) was calculated for the main autonomic variables. According to Cohen method, the effect was considered as small (0.20 to 0.49$)$, medium (0.50 to 0.79), and large ( $>0.80)$ (Cohen., 1988). To conclude, the association between the autonomic response and the ability to generate motor imagery, the mental chronometry, and the level of physical activity was examined using the Pearson's correlation coefficient. A Pearson's correlation coefficient greater than 0.60 is considered to have a strong association, one between 0.30 and 0.60 indicates a moderate association, while less than 0.30 indicates a poor association (Hinkle, Wiersma \& Jurs., 1990). 
281

282 283

284 285

286

287

288

289

290

291

292

293

294

295

296

297

298

299

300

301

302

303

304

305

306

307

\section{Results}

A total of 45 asymptomatic subjects were included in the present study and were randomly assigned to three balanced groups consisting of 15 subjects per group. There were no adverse events or dropouts reported in any of the groups. No statistically significant differences were found in the sociodemographic data $(p>.05)$ (Table 1).

No statistically significant differences were found in any of the baseline measurements between three groups $(p>.05)$ (Table 2). All primary and secondary measures presented a normal distribution $(p>.05)$.

Primary Outcomes

\section{Heart Rate}

The ANOVA revealed significant changes in HR during group*time $\left(F=16.81, p<.01, \eta^{2}=\right.$ $.445)$ and time $\left(F=45.61, p<.01, \eta^{2}=.521\right)$. The post hoc analysis revealed significant intergroup differences between the two intervention groups compared to the $\mathrm{CG}$ with a large effect size $(p<.01, d>0.8)$, although there were no significant differences between them $(p>.05)$. The analysis also revealed statistically significant intra-group differences in both the MI group and the $\mathrm{MI}+\mathrm{AO}$ group in every comparison with a large effect size $(p<.05, d>0.8)$, which did not occur in the $\mathrm{CG}(p>.05)$ (Table 3).

\section{Respiration Rate}

The ANOVA revealed a significant interaction in group*time $\left(F=29.82, p<.01, \eta^{2}=.587\right)$, and in time $\left(F=85.57, p<.01, \eta^{2}=.671\right)$. The post hoc analysis revealed significant inter-group differences between the two intervention groups compared to the CG with a large effect size ( $p<$ $.01, d>0.8)$, although there were no significant differences between the two groups $(p>.05)$. The analysis also revealed statistically significant intra-group differences in both the MI group and the $\mathrm{MI}+\mathrm{AO}$ group in every comparison with a large effect size $(p<.05, d>0.8)$, which was slightly higher in the combined group, and there were no significant differences in the CG $(p>$ .05) (Table 3).

\section{Electrodermal Activity}


308 There were significant differences in time $\left(F=3.95, p<.05, \eta^{2}=.08\right)$, and in group* time $(F=$ $\left.3096.65, p<.01, \eta^{2}=.241\right)$. No statistically significant differences were found between the two 310 intervention groups $(p>.05)$, but some differences were encountered between both groups and 311 the $\mathrm{CG}$, in the first and second interventions, compared to the initial measure with a large effect

312 size for both groups $(p<.05, d>0.8)$, although this was not the case in the return to calm $(p>$ 313 .05). At the intra-group level, both the combined MI + OA and MI alone showed significant 314 changes between the two interventions and the initial measurement, while these changes were 315 not found in the CG $(p>.05)$ (Table 4). All values are in Table 5.

\section{Secondary Outcomes}

317 In the correlation analysis, no association was found between the ANS response and the ability to 318 generate motor images $(p>.05)$. However, regarding mental chronometry, it was found that 319 there is a moderate-strong positive association in the MI group with respect to HR increase $(p<$ $320.05, r=.643), \mathrm{RR}$ and the time spent for performing each MIQ-R task $(p<.05, r=.575)$.

321 Regarding the level of physical activity, based on the data obtained, there appears to be a 322 moderate-strong association between a higher IPAQ score and a higher HR in the MI $(p<.05, r$ $323=.559)$ and $\mathrm{MI}+\mathrm{AO}(\mathrm{p}<.05, r=.621)$ groups, even though no correlation was found in the 324 other variables.

\section{Discussion}

326 The main objective of this study was to observe whether an MI intervention, together with in AO 327 training, caused an increase in the ANS response greater than a MI intervention in isolation in 328 asymptomatic subjects. The findings suggest that in both intervention groups (IM and IM + OA) 329 there is an increase in the vegetative response compared to the CG but there were no significant 330 differences between the two groups in all ANS measures.

331 The findings obtained in the present study show controversy regarding the current state of the art, 332 in which a large number of studies have shown that the combined practice of MI, together with $\mathrm{AO}$, cause an increase in neurophysiological activity greater than the isolated MI (Sakamoto et al., 2009; Vogt et al., 2013). A possible answer to this finding could be given in relation to the 
336 common: they are habitual motor gestures with a low complexity, they do not require a great

337 mental effort in order to carry out the training, and they are not tasks of high intensity.

\section{Complexity of Movement}

339 The movements chosen to carry out the mental practice in the present study were movements 340 that were easy to perform, comfortable, daily, and at a neurophysiological level, they were

341

342

343

344

345

346

347

348

349

350

351

352

353

354

355

356

357

358

359

360

361

362

363

364

365 movements with a broad subcortical participation, minimizing the requirements of cortical activity, which included raising the right knee as high as possible and bending the trunk while trying to touch the toes with the hands. The data revealed that all the groups started from medium-high levels of physical activity. Several studies have suggested that higher levels of physical activity are associated with a greater ability to generate mental motor images (Robin et al., 2007; Di Corrado, Guarnera \& Quartiroli., 2014$).$ The hypotheses to be able to explain this finding reside in relation to the differences in perception and somatosensory afferent integration of the body as well as the processing and control of the voluntary movement, neurophysiological mechanisms widely related to the ability to generate mental motor images. Therefore, the authors of the present study hypothesize that the movements chosen for mental practice did not present any complexity for the participants and they were widely automated. In relation to this, Kuhtz-Buschbeck et al. (2003) used functional magnetic resonance imaging (fMRI) to observe cortical activity during MI while performing simple and high-complexity tasks. They found that at the neurophysiological level, premotor, posterior parietal and cerebellar regions were significantly more active during motor imagery of complex movements than during mental rehearsal of the simple task.

Demougeot et al (2009) obtained that imagined wrist cyclic movements, which are easy to visualise and have a very low intensity, did not provoke any variation in the HR compared to the control group, however, during mental simulation of greater complexity, such as trunk or leg movements against gravity, physiological parameters (e.g., AP and HR) significantly increased. In this study, digital motor gestures are performed even less intensely than those used in our study, which may be the explanation of the results obtained. Moreover, it has been demonstrated that MI combined with AO training is able to achieve a motor learning greater than the two interventions in an isolated way (Smith \& Holmes., 2004; Wright \& Smith., 2009; Eaves et al., 2016). Holmes \& Calmels (2008) argued that in tasks of high complexity, providing a visual 
366 input through the AO facilitates their subsequent motor imagination, as it eliminates the need for

367 visual imagination, allowing, therefore, the attentional focus of the imagery to concentrate on the 368 kinesthetic subdomain.

369 A possible answer to this finding could be that imagined movements, the visual input that is 370 obtained after AO training in a widely integrated and automated motor gesture, does not provide 371 relevant visual information that facilitates the later imagination of the gesture, and therefore both 372 the combined group and the group with the MI training in isolation undergo the same changes 373 concerning the vegetative response. Thus, in more complex motor tasks, AO training in 374 combination with MI would cause a greater autonomic response than MI in isolation. Therefore, 375 movement complexity is a limited factor in the present study; more complex movements should 376 have been used in the present study to verify this finding.

377

378

\section{Mental Effort and Intensity}

Decety et al (1991) found that the self-representation of walking activated the SNS, and that both HR and RR varied with the degree of mental effort of the representation as well as with the intensity of the action during the mental simulation of locomotion. In addition, Paccalin \& Jeannerod (2000) obtained that the RR in subjects that were visualizing people running on a treadmill increased as the intensity of the observed exertion did. Therefore, the intensity of the changes caused in the ANS is closely related to the observed effort, which is greater when the action requires a greater effort.

Bolliet et al. (2005) found that participants, when they observed squats at both $50 \%$ and $90 \%$ of the personal best mark, had ANS responses that varied as a function of movement intensity: autonomic responses recorded during movement observation at $90 \%$ were significantly greater and longer than those recorded during movement observation at 50\%. They concluded that autonomic responses were strongly linked to the amount of observed effort. These data could be correlated with those obtained in the present study, although it would have been necessary to include exercises that require greater effort to obtain stronger conclusions. Finally, regarding mental effort, a recent study performed by Wriessnegger et al. (2017) examined, at a cortical level, force-related hemodynamic changes during the performance of a motor execution and MI task by means of multichannel functional near-infrared spectroscopy. It was found that the most 
395 396

397

398

399

400

401

402

403

404

405

406

407

408

409

410

411

412

413

414

415

416

417

418

419

420

421

422

423

difficult mental task, which needed greater mental effort to perform, led to higher oxygenhemoglobin concentration changes.

\section{Electrodermal Activity: Unique Innervation}

Electrodermal activity is one of the most studied and relevant measures when assessing the activation of the SNS. The reason for this assertion is that the variations in EDA arise from the activity of the sweat glands, which have an exclusively sympathetic innervation. This is an exception, since usually the sympathetic responses can be modulated by a parasympathetic response, as it occurs with the HR or the RR. However, as for the EDA, this double innervation does not occur, and the decrease in the activity of the sweat glands is produced by the cessation of sympathetic innervation (Shields et al., 1987). Consequently, it is suspected that the increase in the EDA supposes a physiological change in SNS prior to the accomplishment of a movement, and that increase might be preceded by a cortical level processing. (Vissing, Scherrer \& Victor, 1991; Vissing \& Hjortsø, 1996; Critchley, 2002). The results here in obtained for the EDA follow in agreement with the findings described in the scientific literature since Di Rienzo et al (2015) and Oishi, Kasai \& Maeshima (2000) reported increases in the electrodermal response after the completion of a protocol of motor imagery.

It should be noted, however, that no significant differences were found between the two intervention groups in the results of the EDA. This may be due to the fact that, as Tremayne \& Barry (2001) found, the increases in EDA depend on the cortical regulation of the ANS and, hence, on the planning of the energy expenditure to be performed depending on the needs of the task being executed. The reason for this difference in the values obtained could be due to the fact that the movements included in the protocol of our study are of low intensity and widely integrated in subcortical structures, and said tasks would not require any energy expenditure or any great previous electrodermic preparation.

In addition, Guillot et al (2008) based on simple movements, concluded that subjects who had not been trained in a motor imagery process had lower values in the EDA compared to subjects who had been trained prior to the imaging process. This result suggests the importance not only of the type of task, but also of the mental effort and the ability to generate motor imagery of the subjects. 
424

425

426

427

428

429

430

431

432

433

434

435

436

437

438

439

440

441

442

443

444

445

446

447

448

449

450

451

452

\section{Ability to Imagine and Level of Physical Activity}

The secondary objective of this research was to observe if there were any relationships between the autonomic response and the ability to generate MI, the mental chronometry, and the level of physical activity.

The scores of both the MIQ-R and the mental chronometry were used with the aim of assessing the ability to generate both kinesthetic and visual MI of the subjects of study. The scores found on the MIQ-R questionnaire were high in all groups, and there were no differences between them, hence showing that the subjects had a great ability to generate MI. The results obtained in the study conducted by Peixoto Pinto et al. (2017) and Guillot et al. (2008) were similar to those obtained in the present study. Nonetheless, no correlation was found between the autonomic response and the ability to generate motor imagery. Concerning mental chronometry, the study of correlations showed that the longer the time spent in the practice, the greater the autonomic response obtained. Thus, we can agree that mental effort and attention seem to be very closely related to autonomic response.

Regarding the level of physical activity, the data revealed that all the groups started from medium-high levels of physical activity, with no differences between them. A high level of physical activity correlates with a higher ANS response, as reported by Oishi \& Maeshima (2000). Their study compared professional and novice skaters and it was shown that there was a higher increase in HR and RR in higher levels of physical activity. In addition, Di Corrado, Guarnera \& Quartiroli (2014) found that athletes had higher mean scores on imagery ability than the non-athlete group, suggesting the relationship between physical activity and the ability to generate motor imagery. A moderate-strong association was obtained in both intervention groups, between the HR and the level of physical activity, but neither in the RR nor in EDA, probably because of the characteristics of the motor gestures used for the mental motor task.

\section{Clinical Implications}

The results of this research must be interpreted carefully because the study was conducted with healthy participants. It is not possible to completely extrapolate the results to patients who have pain or functional disorders. Despite this, the movements used in the present study, lifting the leg and bending the trunk, are widely used in a clinical setting. Thus, if the clinician wants to 
453 perform a mental practice of a simple movement, it is not necessary to perform AO training in 454 addition to MI training, thus optimizing the treatment time.

455 Currently, it is unknown whether $\mathrm{MI}$ and $\mathrm{AO}$ might play a role as a cognitive tool in 456 rehabilitation. It is therefore relevant to the theoretical explanation of MI and AO to increase 457 knowledge about ANS activity. These findings could be useful in the therapeutic use of MI and $458 \mathrm{AO}$ as cognitive tools in rehabilitation, providing further clues about movement complexity and 459 intensity for clinical use.

460 ANS activation during mental practice could provide useful indications to clinicians for the level 461 of effort that patients develop during rehabilitation by means of mental training. This can help to 462 optimize mental training and to minimize discomfort or fatigue for patients, as Demougeot et al., 4632009 , argued.

464 MI therefore enables the practice of movements without the need to physically perform them, 465 and has been widely used in the training of technical skills to athletes and musicians, as well as

466

467

468

469

470

471

472

473

474

475

476

477

478

479 in neurorehabilitation (Calmels et al., 2006). In the field of sports fitness, numerous research studies have suggested that MI accelerates and improves sports performance and the learning of motor skills. Mental practice has also been shown to improve (at the psychosocial level) athletes' motivation and confidence, thereby reducing the anxiety inherent in a competitive event (Guillot and Collet, 2008; Ridderinkhof and Brass, 2015). It could be used clinically to improve the psychosocial sphere of patients through a mental practice adapted to them.

Finally, MI could be considered a complement to physical training because the combination of the two has been widely shown to be more effective in terms of performance than isolated physical training (Feltz and Landers, 1983). Thus, MI could have an impact on rehabilitation to improve performance in patients seeking to achieve physical goals.

\section{Limitations}

One limitation of our study was that a movement of greater complexity and intensity could have been included to be able to compare the results between groups and to verify their influence in relation to the response of the ANS. Movement complexity should be considered as a dependent 
480 variable to be tested in future research. We also consider that it is necessary to evaluate the ANS

481 activity evoked by mental practice according to the different levels of previous physical activity.

482 Moreover, our results do not allow us to isolate the effects of only AO in ANS activity. It could 483 be interesting in future research to perform an isolated $\mathrm{AO}$ intervention to test how it influences 484 ANS activity. Another limitation was the impossibility of performing masking in the present 485 study. Finally, a placebo intervention was not performed for the CG. It would have been 486 interesting to record the changes in a placebo intervention for the CG.

\section{Conclusions}

488 Our results suggest that $\mathrm{MI}$, both in isolation and in combination with AO training, trigger the 489 excitatory activation of the SNS, although there are no significant differences between the two intervention groups when using two simple and daily movements that are recorded in the revised movement imagery questionnaire in third-person perspective.

Based on the results obtained, a higher level of physical activity seems to be associated to a higher increase in heart rate. The same occurs with mental chronometry, which seems to show a greater sympathetic activation the longer the time invested in the task and, thus, the greater the mental effort invested on it. Lastly, there seems to be no association between the ability to generate motor imagery and the response of the ANS based on the revised movement imagery questionnaire.

Future research is necessary in order to be able to contrast these results and to allow a better understanding of how the ANS operates and its relation to mental practice. 
500

501

502

503

504

505

506

507

508

509

510

511

512

513

514

515

516

517

518

519

520

521

522

523

524

525

526

\section{References}

Beyer L, Weiss T, Hansen E, Wolf A, Seidel A. 1990. Dynamics of central nervous activation during motor imagination. International Journal Psychophysiology 9:75-80.

Bolliet O, Collet C, Dittmar A. 2005. Observation of Action and Autonomic Nervous System Responses. Perceptual and Motor Skills 101:195-202.

Boucsein W, Fowles DC, Grimnes S, Ben-Shakhar G, roth WT, Dawson ME, Filion DL, Society for Psychophysiological Research Ad Hoc Committee on Electrodermal Measures. 2012. Publication recommendations for electrodermal measurements. Psychophysiology 49:10171034.

Brown R, Kemp U, Macefield V. 2013. Increases in muscle sympathetic nerve activity, heart rate, respiration, and skin blood flow during passive viewing of exercise. Frontiers in Neuroscience 7:102.

Buccino G. 2014. Action observation treatment: a novel tool in neurorehabilitation. Philosophical Transactions of the Royal Society of London. Series B, Biological Sciences 369:20130185-20130185.

Bunno Y, Suzuki T, Iwatsuki H. 2015. Motor imagery muscle contraction strength influences spinal motor neuron excitability and cardiac sympathetic nerve activity. Journal of Physical Therapy Science 27:3793-3798.

Calmels C, Holmes P, Lopez E, Naman V. 2006. Chronometric Comparison of Actual and Imaged Complex Movement Patterns. Journal of Motor Behavior 38(5):339-48.

Campos A, González MA. 2010. Spanish version of the revised movement image questionnaire (miq-r): psychometric properties and validation. Revista de Psicología del Deporte 19:263273.

Cohen J. 1988. Statistical power analysis for the behavioral sciences, 2nd ed. Hillsdale, NJ: Lawrence Erlbaum Associates.

Collet C, Di Rienzo F, El Hoyek N, Guillot A. 2013. Autonomic nervous system correlates in movement observation and motor imagery. Frontiers in Human Neuroscience 7:415. 
527 Critchley HD. 2002. Review: Electrodermal Responses: What Happens in the Brain. 528 Neuroscience 8:132-142.

529 Decety J. 1996. The neurophysiological basis of motor imagery. Behavioral Brain Research $530 \quad 77: 45-52$.

531 Decety J, Jeannerod M, Durozard D, Baverel G. 1993. Central activation of autonomic effectors 532 during mental simulation of motor actions in man. The Journal of Physiology 461:549-563.

533 Decety J, Jeannerod M, Germain M, Pastene J. 1991. Vegetative response during imagined 534 movement is proportional to mental effort. Behavioral Brain Research 42:1-5.

535 Demougeot L, Normand H, Denise P, Papaxanthis C. 2009. Discrete and Effortful Imagined 536 Movements Do Not Specifically Activate the Autonomic Nervous System. PLoS One $537 \quad 26 ; 4(8): \mathrm{e} 6769$.

538

539

540

541

542

543

544

545

546

547

548

549

550

551

552

553 554

Di Corrado D, Guarnera M, Quartiroli A. 2014. Vividness and Transformation of Mental Images in Karate and Ballet. Perceptual and Motor Skills 119:764-773.

Di Rienzo F, Blache Y, Kanthack TFD, Monteil K, Collet C, Guillot A. 2015. Short-term effects of integrated motor imagery practice on muscle activation and force performance. Neuroscience 305:146-156.

Eaves DL, Haythornthwaite L, Vogt S. 2014. Motor imagery during action observation modulates automatic imitation effects in rhythmical actions. Frontiers in Human Neuroscience. 8:28.

Eaves DL, Riach M, Holmes PS, Wright DJ. 2016. Motor Imagery during Action Observation: A Brief Review of Evidence, Theory and Future Research Opportunities. Frontiers in Neuroscience 10:514.

Faul F, Erdfelder E, Lang A-G, Buchner A. 2007. G*Power 3: a flexible statistical power analysis program for the social, behavioral, and biomedical sciences. Behavioral Research Methods 39:175-191.

Feltz DL, Landers DM. 1983. The effects of mental practice on motor skill learning and performance: A meta-analysis. Journal of Sport Psychology. 25-57.

Guillot A, Collet C. 2005a. Contribution from neurophysiological and psychological methods to the study of motor imagery. Brain Research Reviews 50:387-397. 
555 Guillot A, Di Rienzo F, Macintyre T, Moran A, Collet C. 2012. Imagining is Not Doing but 556 Involves Specific Motor Commands: A Review of Experimental Data Related to Motor 557 Inhibition. Frontiers in Neuroscience 6:247.

558 Guillot A, Collet C. 2005b. Duration of Mentally Simulated Movement: A Review. Journal of 559 Motor Behavior 37:10-20.

560 Guillot A, Collet C, Nguyen VA, Malouin F, Richards C, Doyon J. 2008. Functional 561 neuroanatomical networks associated with expertise in motor imagery. Neuroimage 562 41:1471-1483.

563

564

565

566

567

568

569

570

571

572

573

574

575

576

577

578

579

580

581

582

Guillot A, Collet C. 2008. Construction of the Motor Imagery Integrative Model in Sport: a review and theoretical investigation of motor imagery use. International Review of Sport and Exercise Psychology 1(1):31-44.

Hinkle DE, Wiersma W, Jurs SG. 1990. Applied Statistics for the Behavioral Sciences. Journal of Educational and Behavioral Statistics 15:84-87.

Holmes P, Calmels C. 2008. A Neuroscientific Review of Imagery and Observation Use in Sport. Journal of Motor Behavior 40:433-445.

Jeannerod M. 2001. Neural Simulation of Action: A Unifying Mechanism for Motor Cognition. Neuroimage 14:103-109.

Kuhtz-Buschbeck JP, Mahnkopf C, Holzknecht C, Siebner H, Ulmer S, Jansen O. 2003. Effector-independent representations of simple and complex imagined finger movements: a combined fMRI and TMS study. The European Journal of Neuroscience 18(12):3375-87.

La Touche R, París-Alemany A, Mannheimer JS, Angulo-Díaz-Parreño S, Bishop MD, LopézValverde-Centeno A, von Piekartz H, Fernández-Carnero J. 2013. Does Mobilization of the Upper Cervical Spine Affect Pain Sensitivity and Autonomic Nervous System Function in Patients With Cervico-craniofacial Pain? Clinical Journal of Pain 29:205-215.

Lang PJ, Greenwald MK, Bradley MM, Hamm AO. 1993. Looking at pictures: affective, facial, visceral, and behavioral reactions. Psychophysiology 30:261-273.

Lotze M, Montoya P, Erb M, Hülsmann E, Flor H, Klose U, Birbaumer N, Grodd W .1999. Activation of Cortical and Cerebellar Motor Areas during Executed and Imagined Hand 
Luft AR, Skalej M, Stefanou A, Klose U, Voigt K. 1998. Comparing motion- and imagery585 related activation in the human cerebellum: a functional MRI study. Human Brain Mapping

587

588

589

590

591

592

593

594

595

596

597

598

599

600

601

602

603

604

605

606

607

608

609

610 6:105-113.

Malouin F, Richards CL, Durand A, Doyon J. 2008. Reliability of Mental Chronometry for Assessing Motor Imagery Ability After Stroke. Archives of Physical Medicine and Rehabilitation 89:311-319.

Niendorf T, Winter L, Frauenrath T. 2012. Electrocardiogram in an MRI Environment: Clinical Needs, Practical Considerations, Safety Implications, Technical Solutions and Future Directions. In: Advances in Electrocardiograms - Methods and Analysis. InTech.

Oishi K, Kasai T, Maeshima T. 2000. Autonomic response specificity during motor imagery. Journal of Physiological Anthropology and Applied Human Science 19:255-261.

Paccalin C, Jeannerod M. 2000. Changes in breathing during observation of effortful actions. Brain Research 862:194-200.

Papadelis C, Kourtidou-Papadeli C, Bamidis P, Albani M. 2007. Effects of imagery training on cognitive performance and use of physiological measures as an assessment tool of mental effort. Brain and Cognition 64:74-85.

Peixoto Pinto T, Mello Russo Ramos M, Lemos T, Domingues Vargas C, Imbiriba LA. 2017. Is heart rate variability affected by distinct motor imagery strategies? Physiology \& Behavior 177:189-195.

Ridderinkhof KR, Brass M. 2015. How Kinesthetic Motor Imagery works: A predictiveprocessing theory of visualization in sports and motor expertise. The Journal of Physiology 109(1-3):53-63.

Rizzolatti G, Sinigaglia C. 2010. The functional role of the parieto-frontal mirror circuit: interpretations and misinterpretations. Nature Reviews Neuroscience 11:264-274.

Robin N, Dominique L, Toussaint L, Blandin Y, Guillot A, Her M Le. 2007. Effects of motor imagery training on service return accuracy in tennis: The role of imagery ability. International Journal of Sport and Exercise Psychology 5:175-186. 
611 Roman-Viñas B, Serra-Majem L, Hagströmer M, Ribas-Barba L, Sjöström M, Segura-Cardona 612 R. 2010. International Physical Activity Questionnaire: Reliability and validity in a Spanish 613 population. European Journal of Sport Science 10:297-304.

614 Sakamoto M, Muraoka T, Mizuguchi N, Kanosue K. 2009. Combining observation and imagery 615 of an action enhances human corticospinal excitability. Neuroscience Research 65:23-27.

616 Schulz KF, Altman DG, Moher D, CONSORT Group. 2010. CONSORT 2010 Statement: 617 updated guidelines for reporting parallel group randomised trials. Trials 11:32.

618 Shields SA, MacDowell KA, Fairchild SB, Campbell ML. 1987. Is mediation of sweating 619 cholinergic, adrenergic, or both? A comment on the literature. Psychophysiology 24:312$620 \quad 319$.

621

Smith D, Holmes P. 2004. The Effect of Imagery Modality on Golf Putting Performance. Journal

623

624

625

626

627

628

629

630

631

632

633

634

635

636

637

638 of Sport and Exercise Psychology 26:385-395.

Stephan KM, Fink GR, Passingham RE, Silbersweig D, Ceballos-Baumann AO, Frith CD, Frackowiak RS. 1995. Functional anatomy of the mental representation of upper extremity movements in healthy subjects. Journal of Neurophysiology 73:373-386.

Taube W, Mouthon M, Leukel C, Hoogewoud H-M, Annoni J-M, Keller M. 2015. Brain activity during observation and motor imagery of different balance tasks: An fMRI study. Cortex 64:102-114.

Thill EE, Bryche D, Poumarat G, Rigoulet N. 1997. Task-involvement and ego-involvement goals during actual and imagined movements: their effects on cognitions and vegetative responses. Behavioral Brain Research 82:159-167.

Tremayne P, Barry RJ. 2001. Elite pistol shooters: physiological patterning of best vs. worst shots. International Journal of Psychophysiology 41:19-29.

Vissing SF, Hjortsø EM. 1996. Central motor command activates sympathetic outflow to the cutaneous circulation in humans. Journal of Physiology 1:931-939.

Vissing SF, Scherrer U, Victor RG. 1991. Stimulation of skin sympathetic nerve discharge by central command. Differential control of sympathetic outflow to skin and skeletal muscle during static exercise. Circulation Research 69:228-238. 
639 Vogt S, Rienzo F Di, Collet C, Collins A, Guillot A. 2013. Multiple roles of motor imagery 640 during action observation. Frontiers in Human Neuroscience 7:807.

641 Williams SE, Guillot A, Di Rienzo F, Cumming J. 2015. Comparing self-report and mental 642 chronometry measures of motor imagery ability. European Journal of Sport Science $643 \quad 15: 703-711$.

644 Wong SW, Massé N, Kimmerly DS, Menon RS, Shoemaker JK. 2007. Ventral medial prefrontal 645 cortex and cardiovagal control in conscious humans. NeuroImage 35:698-708.

646 Wriessnegger SC, Kirchmeyr D, Bauernfeind G, Müller-Putz GR. 2017. Force related 647 hemodynamic responses during execution and imagery of a hand grip task: A functional 648 near infrared spectroscopy study. Brain and Cognition, 117, 108-116.

649 Wright CJ, Smith D. 2009. The effect of PETTLEP imagery on strength performance. 650 International Journal of Sport and Exercise Psychology 7:18-31.

651 Wright DJ, Williams J, Holmes PS. 2014. Combined action observation and imagery facilitates 652 corticospinal excitability. Frontiers in Human Neuroscience 8:951. 


\section{Table 1 (on next page)}

Descriptive statistics of socio-demographic data. 
1

2

3

4

5

6

7

8

9

10

11

12

13

14

15

16

17

18

19

20

MI+AO: Motor Imagery and Action Observation; CG: Control Group.

Table 1. Descriptive statistics of socio-demographic data.

\begin{tabular}{|c|c|c|c|c|}
\hline Measures & $\begin{array}{c}\text { MI Group } \\
(\mathrm{n}=15)\end{array}$ & $\begin{array}{c}\text { MI+AO Group } \\
(\mathrm{n}=15)\end{array}$ & $\begin{array}{l}\text { Control Group } \\
\qquad(\mathrm{n}=15)\end{array}$ & $p$ value \\
\hline Age & $37.07 \pm 13.86$ & $37.93 \pm 13.17$ & $38.47 \pm 13.67$ & .960 \\
\hline Height & $166.87 \pm 5.20$ & $167.60 \pm 6.40$ & $168.27 \pm 9.40$ & .870 \\
\hline Weight & $63.73 \pm 15.31$ & $66.80 \pm 11.89$ & $68.6 \pm 12.45$ & .768 \\
\hline Gender & & & & .293 \\
\hline Male & $4(26.7)$ & $5(33.3)$ & $8(53.3)$ & \\
\hline Female & $11(73.3)$ & $10(66.7)$ & $7(46.7)$ & \\
\hline Educational Level & & & & .399 \\
\hline Primary education & $1(6.7)$ & $0(0.0)$ & $0(0.0)$ & \\
\hline Secondary education & $5(33.3)$ & $6(40.0)$ & $9(60.0)$ & \\
\hline College education & $9(60.0)$ & $9(60.0)$ & $6(40.0)$ & \\
\hline
\end{tabular}

21

22

23

24

25

26

27

28

29

30

31

32

33

34

35

36

37

38

39

40

41 


\section{Table 2 (on next page)}

Descriptive statistics of self-report and baseline autonomic sympathetic-excitatory outcomes. 
1 Table 2. Descriptive statistics of self-report and baseline autonomic sympathetic-excitatory outcomes.

\begin{tabular}{|c|c|c|c|c|}
\hline Measures & $\begin{array}{c}\text { MI Group } \\
(\mathrm{n}=15)\end{array}$ & $\begin{array}{c}\text { MI+AO Group } \\
(\mathrm{n}=15)\end{array}$ & $\begin{array}{c}\text { Control Group } \\
(\mathrm{n}=15)\end{array}$ & $p$ value \\
\hline HR & $70.10 \pm 7.79$ & $66.73 \pm 11.01$ & $75.00 \pm 11.78$ & .101 \\
\hline $\mathbf{R R}$ & $13.71 \pm 2.34$ & $13.2 \pm 1.83$ & $13.7 \pm 1.84$ & .758 \\
\hline EDA & $0.85 \pm 1.33$ & $0.97 \pm 1.28$ & $1.34 \pm 0.93$ & .510 \\
\hline \multicolumn{5}{|l|}{ MIQ-R } \\
\hline MIQR-K & $24.27 \pm 3.34$ & $24.47 \pm 3.29$ & $24.27 \pm 3.82$ & .984 \\
\hline MIQR-KT & $13.91 \pm 9.39$ & $15.49 \pm 9.10$ & $9.38 \pm 4.75$ & .109 \\
\hline MIQR-V & $25.00 \pm 3.04$ & $25.20 \pm 4.03$ & $23.40 \pm 4.43$ & .388 \\
\hline MIQR-VT & $12.26 \pm 8.18$ & $13.62 \pm 7.68$ & $8.99 \pm 4.20$ & .182 \\
\hline IPAQ & & & & .877 \\
\hline Low level & $2(13.3)$ & $1(6.7)$ & $3(20.0)$ & \\
\hline Moderate level & $7(46.7)$ & $8(53.3)$ & $7(46.7)$ & \\
\hline High level & $6(40.0)$ & $6(40.0)$ & $5(33.3)$ & \\
\hline
\end{tabular}

2 Values are presented as mean \pm standard deviation or number (\%); MI: Motor Imagery; MI+AO: Motor Imagery and Action

3 Observation; CG: Control Group; HR: Heart Rate; RR: Respiration Rate; EDA: Electrodermal Activity; MIQ-R: the Revised

4 Movement Imagery Questionnaire; MIQR-K: Kinesthetic subscale; MIQR-KT: Time employed in Kinesthetic subscale; MIQR-

5 V: Visual subscale; MIQR-VT: Time employed in Visual subscale; IPAQ: International Physical Activity Questionnaire 


\section{Table $\mathbf{3}$ (on next page)}

Comparative analysis of the primary outcomes. 
1 Table 3. Comparative analysis of the primary outcomes.

\begin{tabular}{|c|c|c|c|c|c|c|}
\hline Measure & Group & \multicolumn{4}{|c|}{ Mean \pm SD } & \multirow{2}{*}{$\begin{array}{l}\text { Mean Difference( }(95 \% \text { CI); Effect Size (d) } \\
\text { a) (Pre'-Pre) vs. ('stI-Pre) } \\
\text { b) (Pre'-Pre) vs. ( }{ }^{\left({ }^{2 n d} I-P r e\right)} \\
\left.\text { c) ( }{ }^{2 n d} I-P r e\right) \text { vs. (Post-2ndI) }\end{array}$} \\
\hline \multirow{4}{*}{ Heart Rate (Hpm) } & & Pre'-Pre & 1stI-Pre & 2ndI-Pre & Post-2ndI & \\
\hline & MI & $-0.88 \pm 4.70$ & $6.15 \pm 3.43$ & $9.47 \pm 5.32$ & $-6.29 \pm 5.35$ & $\begin{array}{l}\text { a) }-7.04^{*}(-11.62 \text { to }-2.46) ; d=-1.71 \\
\text { b) }-10.35^{* *}(-15.23 \text { to }-5.47) ; d=-2.06 \\
\text { c) } 5.40^{*}(1.34 \text { to } 9.46) ; d=2.95\end{array}$ \\
\hline & $\mathrm{MI}+\mathrm{AO}$ & $-0.23 \pm 2.68$ & $6.80 \pm 6.32$ & $10.10 \pm 5.88$ & $-7.26 \pm 5.28$ & $\begin{array}{l}\text { a) }-7.04^{*}(-11.61 \text { to }-2.47) ; d=-1.44 \\
\text { b) }-10.33^{* *}(-15.22 \text { to }-5.46) ; d=-2.26 \\
\text { c) } 7.03^{* *}(2.97 \text { to } 11.09) ; d=3.10\end{array}$ \\
\hline & CG & $1.46 \pm 3.04$ & $-1.40 \pm 4.03$ & $-2.20 \pm 3.56$ & $-0.66 \pm 2.12$ & $\begin{array}{l}\text { a) } 2.86(-1.71 \text { to } 7.43) ; d=0.80 \\
\text { b) } 3.66(-1.21 \text { to } 8.54) ; d=1.10 \\
\text { c) } 2.21(-1.92 \text { to } 6.19) ; d=-0.52\end{array}$ \\
\hline \multirow{3}{*}{$\begin{array}{l}\text { Mean Difference }(95 \% C I) ; \\
\text { Effect Size }(d)\end{array}$} & $\begin{array}{c}\text { MI vs. MI + } \\
\text { AO } \\
\end{array}$ & $\begin{array}{l}-0.65(-3.91 \text { to } \\
2.61) ; d=-0.17 \\
\end{array}$ & $\begin{array}{l}-0.65(-4.98 \text { to } \\
3.68) ; d=-0.12 \\
\end{array}$ & $\begin{array}{l}-0.63(-5.21 \text { to } \\
3.93) ; d=-0.11\end{array}$ & $\begin{array}{l}0.97(-3.13 \text { to } \\
5.08) ; d=0.18 \\
\end{array}$ & \\
\hline & MI vs. CG & $\begin{array}{l}-2.35(-5.62 \text { to } \\
0.91) ; d=-0.59 \\
\end{array}$ & $\begin{array}{l}7.55^{* *}(3.21 \text { to } \\
11.89) ; d=2.01 \\
\end{array}$ & $\begin{array}{l}11.67^{* *}(7.09 \text { to } \\
16.24) ; d=2.57 \\
\end{array}$ & $\begin{array}{c}-5.62^{*}(-9.73 \text { to } \\
-1.51) ; d=-1.38 \\
\end{array}$ & \\
\hline & $\begin{array}{c}\mathrm{MI}+\mathrm{AO} \text { vs. } \\
\mathrm{CG}\end{array}$ & $\begin{array}{l}1.70(-4.96 \text { to } \\
1.56) ; d=-0.58 \\
\end{array}$ & $\begin{array}{c}8.20^{* *}(3.86 \text { to } \\
12.54) ; d=1.54 \\
\end{array}$ & $\begin{array}{l}12.30^{* *}(7.73 \text { to } \\
16.88) ; d=2.53 \\
\end{array}$ & $\begin{array}{l}-6.60^{*}(-10.71 \text { to } \\
-2.49) ; d=-1.64 \\
\end{array}$ & \\
\hline \multirow{4}{*}{ Respiration Rate (Bpm) } & & Pre'-Pre & 1stI-Pre & 2ndI-Pre & Post-2ndI & $\begin{array}{l}\text { a) (Pre'-Pre) vs. ( }{ }^{\text {stt I-Pre) }} \\
\left.\text { b) (Pre'-Pre) vs. }{ }^{(2 n d} I-P r e\right) \\
\text { c) (2ndI-Pre) vs. (Post-2ndI) }\end{array}$ \\
\hline & MI & $0.06 \pm 1.01$ & $2.67 \pm 1.97$ & $4.34 \pm 2.17$ & $-4.19 \pm 2.08$ & $\begin{array}{l}\text { a) }-2.61^{*}(-4.47 \text { to }-0.74) ; d=-1.66 \\
\text { b) }-4.28^{* *}(-6.19 \text { to }-2.37) ; d=-2.52 \\
\text { c) } 8.54^{* *}(6.10 \text { to } 10.98) ; d=4.01\end{array}$ \\
\hline & $\mathrm{MI}+\mathrm{AO}$ & $0.22 \pm 0.73$ & $3.19 \pm 2.21$ & $5.63 \pm 2.03$ & $-4.53 \pm 2.14$ & $\begin{array}{l}\text { a) }-2.96^{* *}(-4.83 \text { to }-1.09) ; d=-1.80 \\
\text { b) }-5.40^{* *}(-7.31 \text { to }-3.49) ; d=-3.54 \\
\left.\text { c) } 10.16^{* *} \text { (7.72 to } 12.60\right) ; d=4.87\end{array}$ \\
\hline & CG & $0.12 \pm 1.83$ & $-0.46 \pm 1.50$ & $-0.82 \pm 1.79$ & $0.17 \pm 1.26$ & $\begin{array}{l}\text { a) } 0.58 \text { (-1.28 to } 2.44) ; d=0.34 \\
\text { b) } 0.94 \text { (-0.97 to } 2.85) ; d=0.51 \\
\text { c) }-0.99 \text { (-3.43 to } 1.44) ; d=-0.63\end{array}$ \\
\hline \multirow{3}{*}{$\begin{array}{c}\text { Mean Difference }(95 \% \mathrm{CI}) \text {; } \\
\text { Effect Size }(d)\end{array}$} & $\begin{array}{c}\text { MI vs. MI + } \\
\text { AO } \\
\end{array}$ & $\begin{array}{l}-0.16(-1.33 \text { to } \\
1.00) ; d=-0.18\end{array}$ & $\begin{array}{l}-0.52(-2.27 \text { to } \\
1.23) ; d=-0.24 \\
\end{array}$ & $\begin{array}{l}-1.28(-3.11 \text { to } \\
0.54) ; d=-0.61 \\
\end{array}$ & $\begin{array}{l}0.33(-1.37 \text { to } \\
2.03) ; d=0.16\end{array}$ & \\
\hline & MI vs. CG & $\begin{array}{l}-0.06(-1.22 \text { to } \\
1.10) ; d=-0.04 \\
\end{array}$ & $\begin{array}{l}3.13^{* *}(1.38 \text { to } \\
4.88) ; d=1.78 \\
\end{array}$ & $\begin{array}{l}5.16^{* *}(3.33 \text { to } \\
6.99) ; d=2.59 \\
\end{array}$ & $\begin{array}{l}-4.37^{* *}(-6.08 \text { to } \\
-2.66) ; d=-2.53 \\
\end{array}$ & \\
\hline & $\begin{array}{c}\mathrm{MI}+\mathrm{AO} \text { vs. } \\
\text { CG }\end{array}$ & $\begin{array}{l}0.10(-1.06 \text { to } \\
1.27) ; d=0.07\end{array}$ & $\begin{array}{l}3.65^{* *}(1.90 \text { to } \\
5.40) ; d=1.93\end{array}$ & $\begin{array}{l}6.45^{* *}(4.62 \text { to } \\
8.27) ; d=3.37\end{array}$ & $\begin{array}{l}-4.70^{* *}(-6.41 \text { to } \\
-2.99) ; d=-2.62\end{array}$ & \\
\hline
\end{tabular}

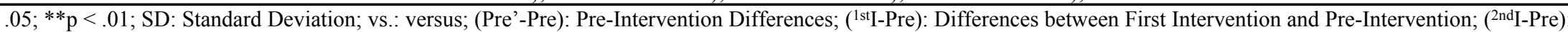

3 Differences between Second Intervention and Pre-Intervention; (Post-2nd): Differences between Post-Intervention and Second Intervention; MI: Motor Imagery; MI+AO: Motor

4 Imagery and Action Observation; CG: Control Group; Hpm: heartbeats per minute; Bpm: breaths per minute. 


\section{Table 4(on next page)}

Comparative analysis of the primary outcomes. 
1 Table 4. Comparative analysis of the primary outcomes.

\begin{tabular}{|c|c|c|c|c|c|c|}
\hline Measure & Group & & Mea & $=$ SD & & Difference(95\%CI); Effect Size \\
\hline \multirow{4}{*}{ Electrodermal Activity $(\mu \mathrm{S})$} & & Pre'-Pre & 1stI-Pre & 2ndI-Pre & Post-2nd I & $\begin{array}{l}\text { a) (Pre'-Pre) vs. (1stI-Pre) } \\
\text { b) (Pre'-Pre) vs. ( }{ }^{\text {nd I-Pre) }} \\
\text { c) }\left({ }^{2 n d} I-P r e\right) \text { vs. (Post-2ndI) }\end{array}$ \\
\hline & MI & $-0.09 \pm 0.22$ & $0.13 \pm 0.31$ & $0.24 \pm 0.56$ & $0.10 \pm 0.21$ & $\begin{array}{l}\text { a) }-0.23^{*}(-0.46 \text { to }-0.02) ; d=-0.81 \\
\text { b) }-0.33^{*}(-0.63 \text { to }-0.03) ; d=-0.77 \\
\text { c) } 0.13(-0.07 \text { to } 0.34) ; d=0.33\end{array}$ \\
\hline & $\mathrm{MI}+\mathrm{AO}$ & $-0.06 \pm 0.12$ & $0.17 \pm 0.26$ & $0.23 \pm 0.34$ & $0.08 \pm 0.11$ & $\begin{array}{l}\text { a) }-0.24^{*}(-0.47 \text { to }-0.19) ; d=-1.13 \\
\text { b) }-0.30^{*}(-0.60 \text { to }-0.04) ; d=-1.13 \\
\text { c) } 0.15(-0.05 \text { to } 0.36) ; d=0.59\end{array}$ \\
\hline & $\mathrm{CG}$ & $0.06 \pm 0.16$ & $-0.12 \pm 0.19$ & $-0.15 \pm 0.19$ & $0.00 \pm 0.10$ & $\begin{array}{l}\text { a) } 0.18(-0.04 \text { to } 0.40) ; d=1.02 \\
\text { b) } 0.21(-0.09 \text { to } 0.51) ; d=1.19 \\
\text { c) }-0.15(-0.36 \text { to } 0.05) ; d=-0.98\end{array}$ \\
\hline \multirow{3}{*}{$\begin{array}{c}\text { Mean Difference(95\%CI); } \\
\text { Effect Size (d) }\end{array}$} & $\begin{array}{c}\text { MI vs. MI + } \\
\text { AO }\end{array}$ & $\begin{array}{l}-0.02(-0.18 \text { to } \\
0.13) ; d=-0.16\end{array}$ & $\begin{array}{l}-0.04(-0.28 \text { to } \\
0.20) ; d=-0.14\end{array}$ & $\begin{array}{l}0.00(-0.36 \text { to } \\
0.37) ; d=0.02\end{array}$ & $\begin{array}{l}0.02(-0.11 \text { to } \\
0.16) ; d=0.11\end{array}$ & \\
\hline & MI vs. CG & $\begin{array}{c}-0.15(-0.3 \text { to } \\
0.07) ; d=-0.78\end{array}$ & $\begin{array}{l}0.25^{*}(0.01 \text { to } \\
0.49) ; d=0.97\end{array}$ & $\begin{array}{l}0.39^{*}(0.03 \text { to } \\
0.76) ; d=0.93\end{array}$ & $\begin{array}{l}-0.10(-0.03 \text { to } \\
0.24) ; d=0.60\end{array}$ & \\
\hline & $\begin{array}{c}\mathrm{MI}+\mathrm{AO} \text { vs. } \\
\mathrm{CG} \\
\end{array}$ & $\begin{array}{l}-0.13(-0.29 \text { to } \\
0.32) ; d=-0.84\end{array}$ & $\begin{array}{l}0.29^{*}(0.06 \text { to } \\
0.54) ; d=1.27\end{array}$ & $\begin{array}{l}0.39^{*}(0.02 \text { to } \\
0.75) ; d=1.38\end{array}$ & $\begin{array}{l}0.08(-0.05 \text { to } \\
0.22) ; d=0.76\end{array}$ & \\
\hline
\end{tabular}

$* \mathrm{p}<.05 ; * * \mathrm{p}<.01 ; \mathrm{SD}$ : Standard Deviation; vs.: versus; (Pre'-Pre): Pre-Intervention Differences; (1stI-Pre): Differences between First Intervention and Pre-Intervention;

3 (2ndI-Pre): Differences between Second Intervention and Pre-Intervention; (Post-2ndI): Differences between Post-Intervention and Second Intervention; MI: Motor Imagery;

4 MI+AO: Motor Imagery and Action Observation; CG: Control Group; $\mu \mathrm{S}$ : Microsiemens. 


\section{Table 5 (on next page)}

Mean values of the dependent variables.

SD: Standard Deviation; Pre and Pre': Pre-Intervention; ${ }^{1 s t}$ : First Intervention; ${ }^{2 n d}$ |: Second Intervention; Post: Post-Intervention; MI: Motor Imagery; MI+AO: Motor Imagery and Action Observation; CG: Control Group; Hpm: heartbeats per minute; Bpm: breaths per minute; $\mu \mathrm{S}$ : microsiemens. 
1 Table 5. Mean values of the dependent variables.

\begin{tabular}{|c|c|c|c|c|c|c|}
\hline Measure & Group & & & & \pm SD & \\
\hline \multirow{4}{*}{ Heart Rate (Hpm) } & & Pre & Pre' & 1stI & 2 2nd $\mathbf{I}$ & Post \\
\hline & MI & $70.10 \pm 7.79$ & $69.51 \pm 7.90$ & $75.67 \pm 6.69$ & $78.98 \pm 7.75$ & $72.69 \pm 7.38$ \\
\hline & $\mathrm{MI}+\mathrm{AO}$ & $66.73 \pm 11.01$ & $66.19 \pm 11.89$ & $73.00 \pm 11.83$ & $76.30 \pm 11.64$ & $69.03 \pm 14.27$ \\
\hline & CG & $75.00 \pm 11.04$ & $76.46 \pm 12.68$ & $75.06 \pm 11.90$ & $74.26 \pm 11.24$ & $73.60 \pm 10.69$ \\
\hline \multirow{4}{*}{ Respiration Rate (Bpm) } & & Pre & Pre' & 1stI & 2ndI & Post \\
\hline & MI & $13.71 \pm 2.34$ & $13.95 \pm 2.10$ & $16.62 \pm 2.23$ & $18.29 \pm 1.87$ & $14.09 \pm 2.16$ \\
\hline & $\mathrm{MI}+\mathrm{AO}$ & $13.20 \pm 1.83$ & $13.31 \pm 1.66$ & $16.50 \pm 2.16$ & $18.94 \pm 1.16$ & $14.41 \pm 2.44$ \\
\hline & $\mathrm{CG}$ & $13.70 \pm 1.84$ & $13.88 \pm 2.05$ & $13.42 \pm 1.86$ & $13.06 \pm 1.62$ & $13.23 \pm 1.64$ \\
\hline \multirow{4}{*}{ Electrodermal Activity $(\mu S)$} & & Pre & Pre' & 1stI & 2ndI & Post \\
\hline & MI & $0.85 \pm 1.33$ & $0.80 \pm 1.23$ & $0.94 \pm 1.51$ & $1.04 \pm 1.74$ & $1.15 \pm 1.94$ \\
\hline & $\mathrm{MI}+\mathrm{AO}$ & $0.97 \pm 1.28$ & $0.86 \pm 1.08$ & $1.04 \pm 1.31$ & $1.09 \pm 1.38$ & $1.18 \pm 1.43$ \\
\hline & CG & $1.34 \pm 0.93$ & $1.40 \pm 0.90$ & $1.28 \pm 0.92$ & $1.25 \pm 0.93$ & $1.25 \pm 0.95$ \\
\hline
\end{tabular}

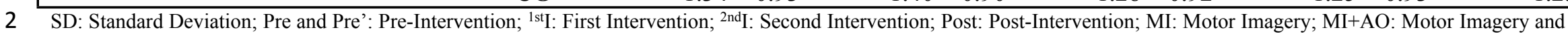

Action Observation; CG: Control Group; Hpm: heartbeats per minute; Bpm: breaths per minute; $\mu \mathrm{S}$ : microsiemens. 
Figure 1

Flow chart of the study design.

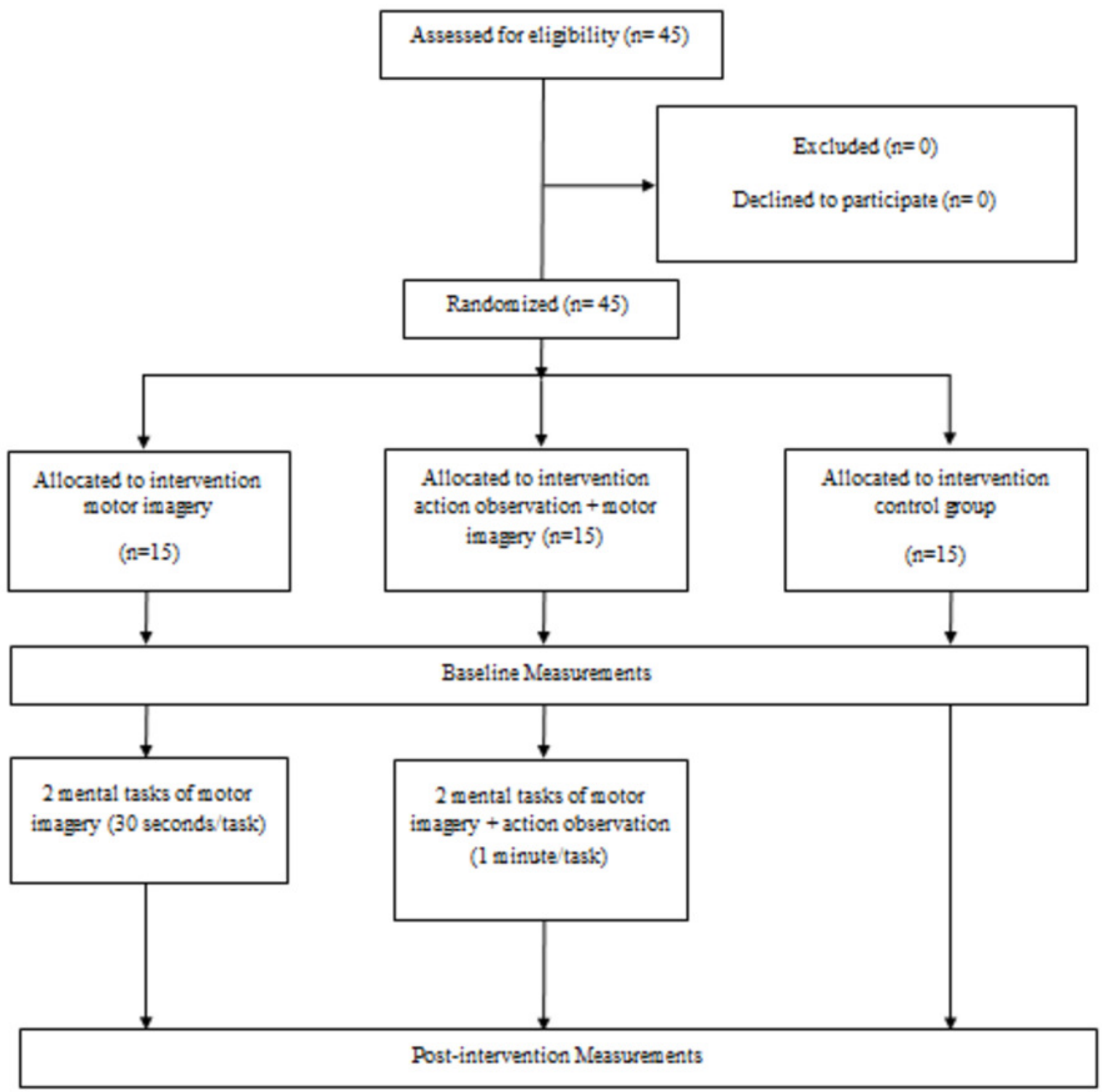


Figure 2

The illustration of the intervention

2A: Motor Imagery; 2B: Action Observation Training
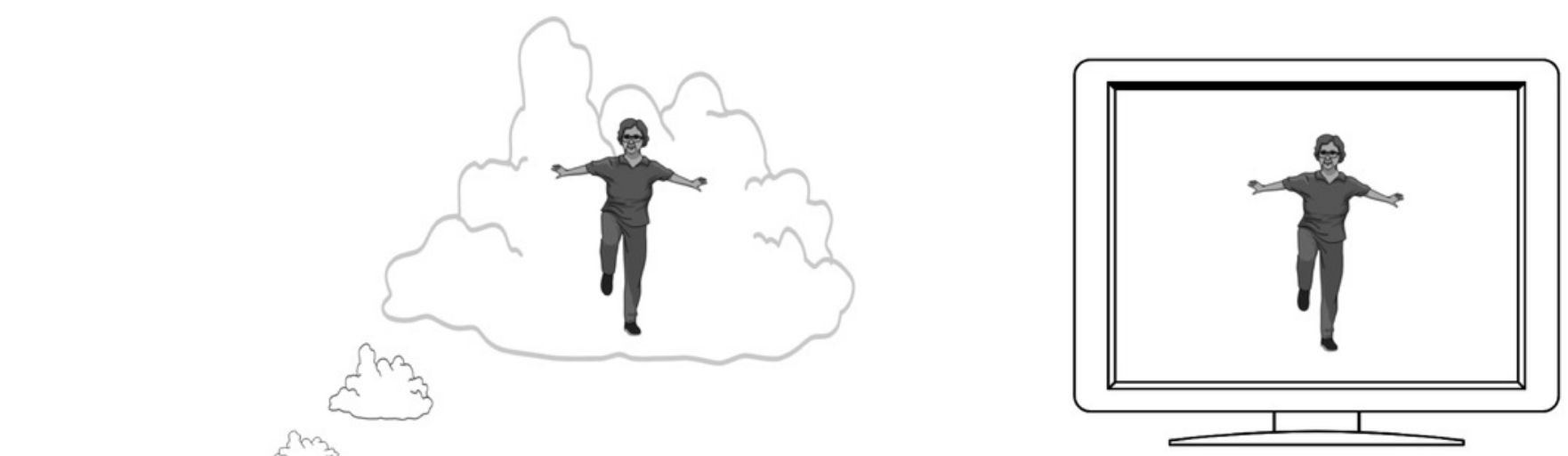

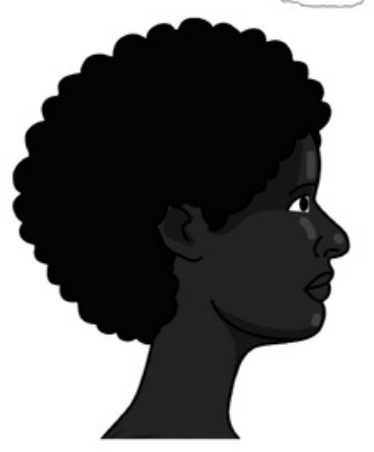

Motor Imagery $\mathbf{2 . A}$

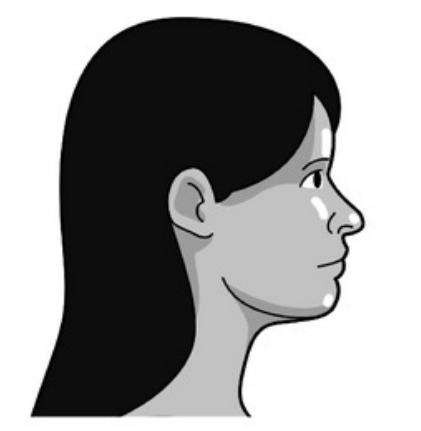

Action Observation $2 . B$

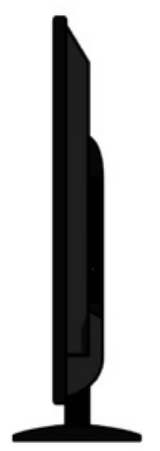

